\title{
On Knowledge-action School-enterprise Cooperation New Mode
}

\author{
Hang Yuan \\ Guangzhou City Construction College, Guangzhou Guangdong, 510925, China
}

\begin{abstract}
Keywords: Knowledge-action, School-enterprise cooperation, New mode marketing
\end{abstract}
\begin{abstract}
How higher vocational education training complex, innovative and development-oriented technical and skilled personnel, strengthens learning and training of expertise and professional competence and effectively cultivates talents with personal competitiveness the society needs through knowledge-action school-enterprise cooperation, is what we vocational educators should focus on to explore, and based on our usual exploration, we sum up, and form new mode of school-enterprise cooperation to be shared, and initiate more resonance to enhance vocational education teaching level.
\end{abstract}

\section{Introduction}

School-enterprise cooperation, knowledge-action, ability-oriented, knowledge-sufficient scale, are the core concepts of higher vocational education, but also are feasible ways to cultivate innovative, complex and development-oriented technical and skilled talents. Various colleges, and even research universities are trying to build "school-enterprise cooperation, professional practice first" application-oriented undergraduate education mode, and how to break the current model and try to integrate school-enterprise resource in our particular environment, achieve school-enterprise integration, to achieve knowledge-action unity, and to more effectively develop vocational students' professional hands-on skills to enhance their consciousness and initiative for learning and capacity cultivation is the problem our vocational education and teaching managers should think about deeply. In this paper, based on the new situation that economic development has entered under the new normal, on how vocational education can effectively enhance school-enterprise cooperation, taking Marketing Major of Guangzhou Urban Construction Vocational Institute for instance, combines teaching practice these years we used for exploration and testing, to summarize and find some available and effective practical modes for dissemination, so as to achieve the effect of throwing a sprat, promote deep and extensive development of school-enterprise cooperation in higher vocational colleges.

\section{Situation and problems of traditional school-enterprise cooperation in higher vocational colleges}

School-enterprise cooperation that higher vocational colleges have started and continued for many years are mostly ongoing with the aim to establish bilateral teaching cooperation, establish school-enterprise cooperation base, look for practical teaching base and practice base for students and even to cope with educational qualification assessment by Ministry of Education, with is more form than function and running relatively superficially. With poor substantiality and systematicness, it is just about one or some aspects of one course or certain ability, and it is short-term or even just about a teaching visit. The effect can be imagined. After several times, students will feel boring, let alone enhance the ability, and in certain cases even eliminate the interest and consciousness of students to enhance professional practice ability. To sum up, the traditional mode of school-enterprise cooperation, has not sufficient motivation to attract students to participate, or systematic training of professional ability, and cannot show fully the initiative role of students. In the entire curriculum, theory and ability profession systematicness is not fully standardized, and do not adapt to learning situation and the needs of society due to the arbitrary curriculum setting.

In order to solve the existing problems, and make school-enterprise cooperation more rational and effective, we curriculum research team used the expertise we learned, and experience in the enterprise, 
and during recent years school teachers went to enterprises to participate in social practice, went deep into society and enterprises, learned about new employment trends, and development trends of professional training needs, mastered talents training demands under the new era, new normal and new economic development situation, used for education reform and research, deepened and sublimed connotation of school-enterprise cooperation, explored the new theory and practice teaching mode and method suitable for marketing profession in our school. We here make a conclusion for discussion, absorption and application by everyone.

\section{Explore and experiment school-enterprise cooperation new mode of higher vocational students of marketing profession}

According to the characteristics of hither vocational education in our school, based on in-depth understanding of student learning characteristics and human nature characteristics, combining with employment needs, we constantly explore and experiment in the teaching practice, and grasp the overall characteristics of contemporary vocational students, such as not liking theory, ambitious, self-centered, fond of performance, lack of ambition, with strong sense of self-protection, fond of the image teaching, only able to timely concentrate, liking teaching method with discussion, less usage of brains and more hands-on practice. In theory teaching, we applied project-oriented, task-promoting, scene settings, more discussion and more hands-on teaching methods. Practical operation combines with theory teaching, and to certain extent the effect is enhanced, but over time, the effect is also discounted. To further enhance the actual work scenarios, highlight students' autonomy, and make participation and responsibilities and rights equal, we had a wide range of exploration, and in-depth study and found some modes and approaches of in-depth cooperation allowing enterprises and schools to try and stick with.

Establish professional short-term order classes, change scenarios, and enhance students' practical competence. Combine with enterprise actual work, based on enterprise project execution, and carry out professional order class with cooperative enterprise. Because in general the project implementation does not take a long time, and do not specify that students have to be employed after graduation, which reduced students' stress of practice due to employment, at the same time arrange short-term business culture education, change school classroom teaching scenes in terms of persons and work, change simple preaching to infusion of business rules and regulations and the overall corporate image, which allows students to have first-line understanding of and grasp content, role, shaping and promotion of corporate image, enables students to develop the personal accomplishment to abide by rules and regulations and safeguard the organization image, also enables them to more intuitively learn and master corporate image design and propaganda.

Then, assign students into the project team to follow up the project, to understand the purpose of marketing, content of marketing and innovation and creativity of marketing planning, to practically learn promotion technology, consumer psychology, advertisement, distribution channel management, internet marketing, etc., and on the job post, specifically and participatorily grasp the content, methods and strategies of the corresponding marketing work. Compared to classroom teaching, the effect is much better. Students can promote their strength and face up to their deficiencies in actual competition work, and learn from the perspective of personal interest. And enterprise will pay for the practice, and also can use a variety of reward and punishment means to carry out education and cultivation of humanity and ethics by hitting students' psychology.

Extensively mine opportunities of enterprises resources used for teaching, and comprehensively train work ability of students. Any enterprise has several functional departments, and for some students who may not like marketing profession, and select wrong profession, we can extensively dig enterprise resources, arrange these students to similar job posts they like, take full advantage of all possible opportunities for all-round development of students, but they still need to learn basic professional knowledge and skills and get assessed, just through this opportunity and resources expand the scope and field of employment of students, and provide individualized instruction for students. Learning with interest has more motivation and better effect. 
At the same time, the field of business cooperation covers all business areas. And the participation of professional school teachers and students to participate in internships can help enterprises find new business opportunities, to work together to develop new products, find new markets, substantially expand cooperation areas, deepen cooperation, give play to students' interest and strengths, and exercise their leadership, organizational ability and social skills. And school-enterprise cooperation pursues win-win. Enterprise provides resources for school, and school can also create wealth for enterprise. Such cooperation can be effective and sustainable.

We cooperated with Guangzhou Lisheng Exhibition Services Ltd. We not only participated in original work, including exhibition booths sales, organization and arrangement of exhibition, carrying out practice of order class, but also cooperated with each other, expanded, and participated in other projects, such as "WETHERM ninth anniversary large-scale branding campaign", students assigned by the school participated in and classroom instructor guided; more than a hundred students who are learning "customer relationship management", "brand planning", "channel management and terminal sales" entered the scene for internship for two days, including brand promotion, customers reception, communication with channel and other practice. They worked as employees, and felt ups and downs in practical work experience, and sense of accomplishment after the transaction. Under the guidance of the instructor, present the course knowledge to students, let them understand in practice, then it will much easier to understand the theory.

The school encourages professional teachers while carrying out school-enterprise cooperation, carry out social services of horizontal issues, based on the actual business situation of cooperative enterprises, solve existing practical professional issues with enterprises, and provide diagnosis of customers relationship management and marketing planning for enterprise; they got benefit of nearly 80,000 Yuan for social services. To some extent, use professional knowledge to help enterprises solve the problem, but also create closer relations with cooperative enterprise, making enterprise-school cooperation closer and more effective;

After intensive contacts with cooperative enterprise, learned about the inconvenience of customers on exhibition, and we with business experts and students found business opportunities, and together invest human resources and financial resources for research. Horizontal cooperation, can not only create new business opportunities, but also exercise the ability to create and observe of professional teachers and students. Through cooperation research, we declared corresponding application-oriented national invention, created new operation areas for enterprise, and got praised by enterprise and school.

Cooperative enterprises to participate in construction work training program, but not the only listen to his words. Joint venture, after all, on behalf of the employer community, and they need to graduate on behalf of the community on their demands, but after graduation students can not or may not be on the job this unit, so only has a representative, listen to others, and then extensively absorb other similar or different types of business marketing this demand for graduates, curriculum design training program by full-time teachers, in order to ensure the necessary expertise and the principles taught.

While cultivating cooperative enterprises and related investigations obtained for students' professional ability, and develop a system of cooperative enterprise with professional capacity-building program, what kind of activities and forms of culture which or which of the ability to highlight specific, so the harvest results. During practice and practice time, in strict accordance with the implementation of training programs to develop good practice teaching to train social needs of professional competence. Which reflects the expertise and professional competence in line with the system for professionals to train community's widow.

From simple off-campus cooperation, joint ventures pulling into the school to school. Through cooperation between enterprises and professional educational philosophy, founded the hospital in the hospital, we have to cooperate with E-House China, the establishment of real estate in our SEM Marketing Institute, enterprise management philosophy, employment standards, quality training and professional education combined to create a real estate marketing professionals training base. 
Contributed to the strong support of business school curricula, integrated teaching game, card integration to corporate sponsors and experts in the form of questions and carry out professional contests and competitions to promote students 'professional learning and professional capacity-building initiative, to enhance students' professional conversion hands ability to effect, guide students to learn professional achievement, innovation and stimulate their professional practice based on professional capacity building. Isa and promote education, while cooperating with the practical operation of part of the professional exam qualifications, for better teaching results. We will organize the school's student conduct market research competition next year, marketing planning competition, network marketing competition, business competition, the students divided into professional and non-professional groups, business experts cooperate topic, do the commentary committee, sponsorship, the school also contributed to the funding of common competition unfold smoothly and efficiently.

Organize students to participate in the province, the country's marketing expertise contest, Department of Steering Group composed of absorbing business people involved in guiding and attract corporate sponsorship, incentives to increase strength, while enterprises with open arms to the winning student, well-paid employment priority, so that we can greatly inspire students to learn professional knowledge, professional ability to cultivate an interest, so as to enhance their learning consciousness and initiative.

Use guide cooperative enterprise, carried out in situ in the campus practice. Full use of school resources and the human resources of these two resources, the creation of the campus combat scenarios, such as cooperation with the supermarket-type business we have established student self management, professional instructor training college campus supermarket, and some lessons especially practice teaching lesson inside can be completed, the students involved, and is autonomous, self-financing, with the independent status of the modern enterprise business person, students can develop the marketing, merchandising and management capacity, and operators should have the discipline, punctuality, efficiency and accountability, teamwork culture.

While taking advantage of the campus of more than ten thousand current and potential needs of staff and students, and make full use of existing resources and school support system of practical teaching requirement, conduct campus fairs twice a year, the introduction of outside enterprises to participate in trade fairs, provided to the students autonomous decision-making, independence and co-operation are outside enterprises to participate in the business environment, competing against fully reflect the level of professional learning and training market research, consumer psychology to grasp, competitive environment analysis, product positioning, marketing strategy, marketing skills, etc. understanding and application, thereby effectively enhance students' professional skills.

Constantly explore and discuss improvements also continue to experiment, we based in Guangzhou Urban Construction College Marketing Major undertaken some reform, but after learning little superficial knowledge, there may be a different school context, does not necessarily have promotional value, but appetizers, mutual learning from each other and improve the level of vocational education and training qualified technical and vocational skills useful talents for the country and society is our aim. We hope that attracted more discussion and consensus.

\section{References}

[1] Song micro investigate the colleges of higher vocational school-enterprise cooperation model. China Adult Education. 2011 (02)

[2] Su Xiaodong, Zhang Canadian music. Exploration and Practice of Vocational Colleges reciprocal school-enterprise cooperation model. Chinese Vocational and Technical Education. 2013 (16)

[3] Xu Bingying. Exploration and Practice of School - enterprise Cooperation Model and Mechanism. Science and Technology Innovation and Application. 2013 (31) 